\title{
Electropherotypes and G-Types of Group A Rotaviruses Detected in Children with Diarrhea in Lagos, Nigeria
}

\author{
Christianah Idowu Ayolabi, ${ }^{1}$ David Ajiboye Ojo, ${ }^{2}$ and George Enyimah Armah ${ }^{3}$ \\ ${ }^{1}$ Department of Microbiology, University of Lagos, Nigeria \\ ${ }^{2}$ Department of Microbiology, University of Agriculture, Abeokuta, Nigeria \\ ${ }^{3}$ Department of Electron Microscopy and Histopathology, Noguchi Memorial Institute for Medical Research, \\ University of Ghana, Accra, Ghana \\ Correspondence should be addressed to Christianah Idowu Ayolabi; ciayolabi@yahoo.co.uk
}

Received 11 October 2013; Accepted 5 November 2013

Academic Editors: D. J. Jackwood and J. Ortego

Copyright (C) 2013 Christianah Idowu Ayolabi et al. This is an open access article distributed under the Creative Commons Attribution License, which permits unrestricted use, distribution, and reproduction in any medium, provided the original work is properly cited.

\begin{abstract}
Approximately over 500,000 children die annually due to severe dehydrating diarrhea caused by rotaviruses. This work investigated rotavirus infection among children less than 5 years with diarrhea in Lagos and determined the circulating electropherotypes and genotypes of the virus isolates. Three hundred and two $(n=302)$ stool samples from children below 60 months were collected from different hospitals and health care centers in Lagos and subjected to enzyme immunoassay (EIA) to determine the presence of Group A rotavirus, RT-PCR to determine the G-types, and polyacrylamide gel electrophoresis (PAGE) to determine the electropherotypes. The results show that $60.3 \%$ of the samples showed distinct rotavirus RNA migration pattern, having long electropherotypes (55.3\%) of seven variations dominating over the short electropherotypes (44.5\%). Six different G-types were detected (G1, G2, G3, G4, G9, and G12). Serotypes G1 and G12 showed long electropherotypic pattern while G2, G3, and G9 exhibited either short or long electropherotype. All G4 detected show short electropherotypic pattern. In conclusion, information on the genomic diversity and RNA electropherotypes of rotaviruses detected in children with diarrhea in Lagos is reported in this study.
\end{abstract}

\section{Introduction}

Rotavirus gastroenteritis is the major cause of morbidity and mortality among infants and young children in both developed and developing countries $[1,2]$. It is estimated that 130 million children develop rotavirus-related diarrhoea each year with 18 million of them experiencing moderate to severe dehydration, resulting in over 520,000 deaths, with $85 \%$ of these deaths occurring in low-income countries $[3,4]$. The mature virus particles are icosahedral, nonenveloped, measure $100 \mathrm{~nm}$ in diameter, and consist of a doublestranded RNA (dsRNA) in the family Reoviridae. It has a distinct morphologic appearance by negative-stain electron microscopy [5]. The viral capsid is triple layered; the inner layer (core) contains the virus genome, which comprises 11 segments of double-stranded RNA, each coding for products that are either structural viral proteins (VP) or nonstructural proteins (NSP). The segmented genome of rotavirus readily reassorts during coinfection, a property that has been used in developing vaccines and undoubtedly plays a role in virus evolution [6].

Studies on the electrophoretic migration patterns of viral genomic dsRNA segments (electropherotyping) have allowed for the classification of rotaviruses into two major groups, the long (L) and the short (S) electropherotypes [7]. Six of these dsRNA segments encode six structural proteins (VP1-VP4, VP6, and VP7), whilst five of them encode five nonstructural proteins (NSP1-NSP5). Of importance, structural proteins VP7 (a glycoprotein or G antigen) and VP4 (the protease sensitive protein or P antigen) make up the outermost layer and are known to induce neutralising and protective antibodies, respectively [8]. VP6 is the most abundant protein [7]. It is stable and has conserved epitopes which makes it a major target in diagnostic assays [9]. In addition, it is highly immunogenic and antigenic; therefore, it may be important in protective immunity. The globally 
common rotavirus strains are G1-G4 with P [4], P [6], and $\mathrm{P} 8$. However, there are over $14 \mathrm{G}$ and $20 \mathrm{P}$ types of rotavirus strains that have been defined $[8,9]$. In Nigeria, reports on the prevalence and characterization of the virus in young children exist [10-13]. However, this study was aimed at extending our knowledge on the epidemiological features of rotavirus infection and providing characteristics of strains infecting pediatric patients in the city of Lagos, Nigeria, based on RNA migration patterns and VP7 genes.

\section{Materials and Methods}

2.1. Study Area and Patients. The study was conducted in Lagos, Southwestern, Nigeria, a commercial capital in Nigeria and it falls within longitude 2.725 to 4.325 East and latitude 6.375 to 6.675 North. The samples for this study were collected in four health institutions in Lagos State, namely, Massey Street Children Hospital (MSCH), Ikorodu, Orile Agege, and Surulere General Hospitals between June 2007 and June 2008. A total of 302 stool specimens were collected from children aged $<5$ years with acute diarrhoea of less than 14-day duration who were treated for dehydration at these hospitals. This study was approved by an ethical medical committee and consents were obtained from parents or legal guardians of the eligible infants before enrolling them.

2.2. Laboratory Analyses. Stool samples were obtained from diarrhea patients into wide mouthed bottle, labeled appropriately, and transferred to the Department of Microbiology laboratory, University of Lagos. An aliquot of each sample was stored at $-20^{\circ} \mathrm{C}$ until being transported on ice to Noguchi Memorial Institute of Medical Research, Ghana, where rotavirus antigen detection and rotavirus strain characterization were performed. Ten percent $(\mathrm{w} / \mathrm{v})$ faecal extracts were screened for the presence of Group A rotavirus antigen using monoclonal antibodies by a commercially available enzyme immunoassay (EIA) kit (Dakopatts, Denmark).

\subsection{Polyacrylamide Gel Electrophoresis (PAGE) Analysis.} Polyacrylamide gel electrophoresis (PAGE) was carried out on the faecal suspensions by the procedure previously described [14]. The dsRNA genome was extracted using phenol-chloroform deproteinization and ethanol precipitation. Extracted viral genome from all EIA rotavirus positive samples was applied to separate lanes of the $10 \%$ polyacrylamide slab and electrophoresed for 18 hours at $100 \mathrm{~V}$ at room temperature using $1 \mathrm{X}$ Tris-glycerine running buffer $(5 \mathrm{mM}$ Tris, $50 \mathrm{mM}$ glycine) in the discontinuous buffer system. The dsRNA segments were visualized by silver staining according to the method described [15].

2.4. Rotavirus G-Typing by PCR. G-type was determined by RT-PCR assays. Briefly, a 1062 bp (full-length) gene segment 9, encoding the VP7 glycoprotein of human Group A rotaviruses, was amplified using the forward primer Beg9 ( $5^{\prime}$-GGC TTT AAA AGA GAG AAT TTC CGT CTG G-3') and the reverse primer End9 $\left(5^{\prime}\right.$-GGT CAC ATC ATA CAA TTC TAA TCT AAG-3'). This was followed by seminested

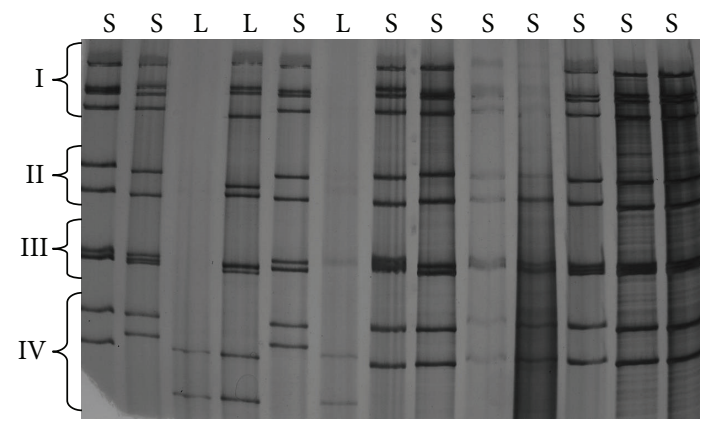

FIGURE 1: Short electrophoretic patterns of Nigerian rotavirus strains determined by PAGE. All strains except for lanes 3, 4, and 6 exhibit short (S) pattern. I, II, III, and IV indicate clusters of migrating gene segments typical of human Group A rotavirus.

PCR using the serotype-specific primers which identify the different $G$ types $[16,17]$. The PCR products were examined after electrophoresis in $1.2 \%$ agarose gels containing $4 \mu \mathrm{g}$ of ethidium bromide/mL. The characterization of the G genotypes amplicons was determined against a $100 \mathrm{bp}$ molecular size marker DNA ladder (Promega).

\section{Results}

A total of 302 stool specimens were analyzed for rotavirus. Seventy-eight (25.8\%) were found to be positive for rotavirus antigen by EIA [10] and, among these positive samples, 47 (60.3\%) showed distinct RNA migration pattern and VP7 rotavirus positive.

3.1. Polyacrylamide Gel Electrophoresis (PAGE). Among the 78 rotavirus stool samples examined by PAGE, 47 yielded typical rotavirus electrophoretic migration profiles while the remaining 31 isolates showed no profile. There were seven variations of long RNA electropherotype occurring in 26 cases and 21 strains with five short patterns (Figures 1 and 2). In general, 12 distinct electrophoretic migration variants were noted. In this hospital-based study, the long electrophoretic profile was the most prevalent rotaviruses in circulation.

3.2. Rotavirus VP7 Genotype Distribution. Forty-two (90\%) of the rotavirus isolates were successfully assigned VP7 Gtype specificity while $5(10 \%)$ showed amplification failure. Six different rotavirus VP7 serotypes including the G9 and G12 which are newly emerging in Africa were detected. In this study, genotypes G1 and G2 occurred predominantly with an equal proportion of $31 \%$ each, followed by G3 (9\%), G4 (5\%), G9 (5\%), and G12 (2\%). Mixed infections (G1 + G2) and G1 $+\mathrm{G} 3$ were also detected in $3(5 \%)$ and $1(2 \%)$ of the samples, respectively (Figure 3 ).

3.3. Rotavirus Electropherotypes and VP7 Genotypes Distributions. Twenty-six (26) samples exhibited classical long electrophoretic profile on PAGE, among which fifteen $(57.7 \%)$ were typed as G1, six as G2 (23.1\%), and one sample each was typed for G3 (3.9\%), G9 (3.9\%), and G12 (3.9\%). Rotavirus 


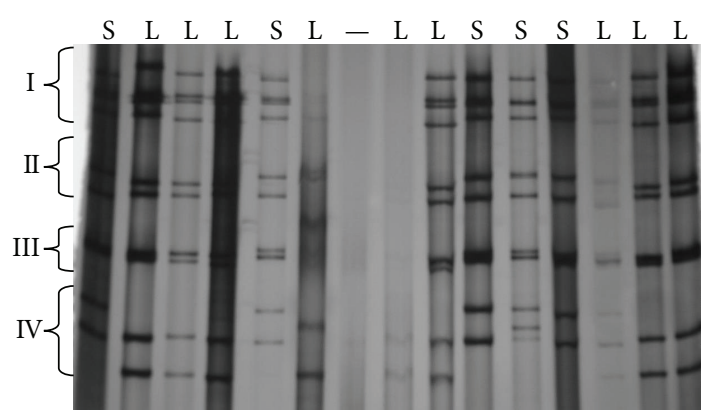

FIGURE 2: Long electrophoretic patterns of Nigerian rotavirus strains, determined by PAGE. All strains except for lanes 1, 5, 10, and 11 exhibit the long (L) pattern. I, II, III, and IV indicate clusters of migrating gene segments typical of human Group A rotavirus.

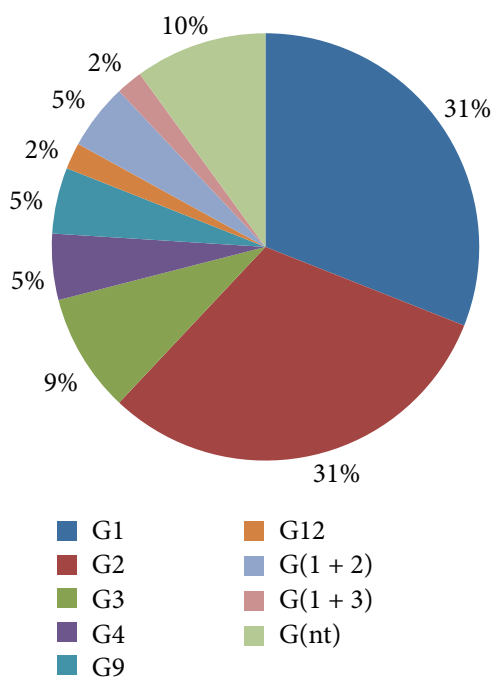

FIGURE 3: Relative frequency of rotavirus G serotypes in stools from children in Lagos, Nigeria.

with dual VP7 specificity of G1 + G2 was also detected in one sample. Only one (3.9\%) of the long electropherotypes could not be typed. Of the 21 samples that showed classical short electrophoretic patterns on PAGE, eight (38.1\%) were typed as G2, two as G9 (9.5\%), one as G3 (4.8\%), and three as G4 (14.3\%) genotypes. Rotavirus with dual VP7 specificity of G1 + G2 and G1 + G3 was also detected in two (9.5\%) and one $(4.8 \%)$ samples, respectively. Four (19\%) of the short electropherotypes could not be assigned any VP7 genotype (Table 1).

\section{Discussion}

Rotaviruses were found to be an important agent of diarrhoea leading to hospitalisation in children less than 5 years of age in Lagos. A $25.8 \%$ of diarrhoea hospitalization was found to be associated with Group A rotavirus infection. The overall detection of rotavirus in $25.8 \%$ of diarrhoea cases is lower than $45 \%$ previously reported in Lagos [12]. This difference observed within Lagos may be due to environmental or
TABLE 1: Electropherotype distribution of rotavirus VP7 genotypes in children in Lagos state.

\begin{tabular}{lcccc}
\hline \multirow{2}{*}{ G-type } & \multicolumn{2}{c}{$n=26$} & \multicolumn{2}{c}{$n=21$} \\
& Long E-type & Percentage & Short E-type & Percentage \\
\hline G1 & 15 & 57.7 & 0 & 0.0 \\
G2 & 6 & 23.1 & 8 & 38.1 \\
G3 & 1 & 3.9 & 1 & 4.8 \\
G4 & 0 & 0.0 & 3 & 14.3 \\
G9 & 1 & 3.9 & 2 & 9.5 \\
G12 & 1 & 3.9 & 0 & 0.0 \\
G(1+2) & 1 & 3.9 & 2 & 9.5 \\
G(1+3) & 0 & 0.0 & 1 & 4.8 \\
G(nt) & 1 & 3.9 & 4 & 19.0 \\
\hline Total & 26 & 55.3 & 21 & 44.6 \\
\hline
\end{tabular}

social factors as there have been great improvement and enlightenment on sanitation in the state, hence the reduction in rotavirus incidence. However, the prevalence observed in this study correlates with other previous studies conducted in other parts of Nigeria, outside Lagos, where prevalence reported had been between $11 \%$ and $37 \%$ [11, 18-20]. Outside Nigeria prevalence of $25.5 \%$ was reported in Ghana [21], 32\% in Kenya [22], and 27.9\% in Abidjan [23].

Reports from different parts of the world have indicated electrotyping as a potential tool for studying the molecular epidemiology of human rotavirus infections $[24,25]$. In this study, 12 different electropherotypes (7 long E-types and 5 short E-types) were found and L5 predominated. The predominance of long pattern over short one, irrespective of the zone of the country, is in accordance with findings of other researchers and it seems to be a norm $[13,26,27]$. There were more electrophoretic patterns observed in this present study than those reported previously in Nigeria [12, 13, 27]. In addition, African rotavirus working group in 1998 reported 2 and 7 patterns from Jos and Zaria, respectively. However, in Bangladesh, 22 electrophoretic patterns were reported and 7 patterns were also reported in Kenya by the same working group [28]. The mechanisms of generating extensive genomic diversity among human rotavirus strains are due to genetic reassortment [29], as genetic rearrangement occurs either naturally or probably due to imposition of pressure by the host immune system [30].

Thirty-one (39.7\%) samples were EIA positive but did not show any RNA pattern on PAGE. This could perhaps be as a result of insufficient intact RNA in the specimens for PAGE to detect, as the sensitivity limit of PAGE stained by the silver nitrate is 3.4ng of viral genomic RNA [15], or may be that the RNA might have been degenerated during storage due to constant power failure in the country.

The globally common and important serotypes G1-G4 in addition to G9 serotype were detected. An unusual rotavirus strain G12 was also identified in this study. It is interesting to state that this is the first time to detect and report serotype G12 specificity in Nigeria. In addition, this is the first single study to record the highest number of different $\mathrm{G}$ serotypes in a single study in the country. In the past 
studies, Audu and colleagues reported 3 different $G$ types (G1 and G3) in Lagos and (G3 and G4) in Ilorin [12], while five different G types (G1, G2, G3, G8, and G9) were also reported by other researchers [31]. This implies that there are diverse strains circulating in Nigeria and this also stresses the need for continuous rotavirus surveillance to better elucidate these new/unusual and emerging strains which may have implication on the available vaccines.

\section{Acknowledgments}

The authors are grateful to staff of the Department of Electron Microscopy and Histopathology, Noguchi Memorial Institute for Medical research, Legon, Ghana, for their technical support. The authors also express their appreciation to the management and staff of all the hospitals where samples were collected and all children who participated in this study. Ethical approval was obtained from Lagos State Hospital Management Board, Nigeria (ref.-SHMB/6/vol VI/912).

\section{References}

[1] C. Bern, J. Martines, I. de Zoysa, and R. I. Glass, "The magnitude of the global problem of diarrhoeal disease: a ten-year update," Bulletin of the World Health Organization, vol. 70, no. 6, pp. 705714, 1992.

[2] U. D. Parashar, C. J. Gibson, J. S. Bresee, and R. I. Glass, "Rotavirus and severe childhood diarrhea," Emerging Infectious Diseases, vol. 12, no. 2, pp. 304-306, 2006.

[3] M. A. Miller and L. McCann, "Policy analysis of the use of hepatitis B, Haemophilus influenzae type-B-, Streptococcus pneumoniae-conjugate, and rotavirus vaccines in national immunization schedules," Health Economics, vol. 9, pp. 19-35, 2000.

[4] K. Molbak, T. K. F. Perch, and C. S. Mikkelsen, "The estimation of mortality due to rotavirus infections in sub-Saharan Africa," Vaccine, vol. 19, no. 4-5, pp. 393-395, 2000.

[5] A. Z. Kapikian and R. M. Chanock, "Rotaviruses," in Fields Virology, vol. 2, pp. 1657-1708, Lippincott-Raven, Philadelphia, Pa, USA, 3rd edition, 1996.

[6] M. K. Estes, "Advances in molecular biology: impact on rotavirus vaccine development," Journal of Infectious Diseases, vol. 174, supplement 1, pp. S37-S46, 1996.

[7] A. Z. Kapikian, R. M. Chanock, and Y. Hoshino, "Rotaviruses," in Fields Virology, pp. 1787-1822, Lippincott Williams \& Wilkins, Philadelphia, Pa, USA, 4th edition, 2001.

[8] Y. Hoshino and A. Z. Kapikian, "Rotavirus serotypes: classification and importance in epidemiology, immunity, and vaccine development," Journal of Health Population and Nutrition, vol. 18, no. 1, pp. 5-14, 2000.

[9] M. K. Estes, G. Kang, C. Q.-Y. Zeng, S. E. Crawford, and M. Ciarlet, "Pathogenesis of rotavirus gastroenteritis," Novartis Foundation Symposium, vol. 238, pp. 82-100, 2001.

[10] C. I. Ayolabi, I. Akpan, D. A. Ojo, G. E. Armah, and R. Emelogwu, "Prevalence of rotavirus among children with diarrhoea in Lagos, Nigeria," in Proceedings of the 4th UNILAG Conference and Fair, pp. 63-70, 2009.

[11] M. Aminu, M. D. Esona, A. Geyer, and A. D. Steele, "Epidemiology of rotavirus and astrovirus infections in children in Northwestern Nigeria," Annals of African Medicine, vol. 7, no. 4, pp. 168-174, 2008.
[12] R. Audu, S. Aremu Omilabu, M. de Beer, I. Peenze, and A. Duncan Steele, "Diversity of human rotavirus VP6, VP7, and VP4 in Lagos State, Nigeria," Journal of Health Population and Nutrition, vol. 20, no. 1, pp. 59-64, 2002.

[13] M. I. Adah, A. Rohwedder, O. D. Olaleye, O. A. Durojaiye, and H. Werchau, "Serotype of Nigerian rotavirus strains," Tropical Medicine and International Health, vol. 2, no. 4, pp. 363-370, 1997.

[14] A. D. Steele and J. J. Alexander, "Molecular epidemiology of rotavirus in black infants in South Africa," Journal of Clinical Microbiology, vol. 25, no. 12, pp. 2384-2387, 1987.

[15] A. J. Herring, N. F. Inglis, C. K. Ojeh, D. R. Snodgrass, and J. D. Menzies, "Rapid diagnosis of rotavirus infection by direct detection of viral nucleic acid in silver-stained polyacrylamide gels," Journal of Clinical Microbiology, vol. 16, no. 3, pp. 473-477, 1982.

[16] V. Gouvea, R. I. Glass, P. Woods et al., "Polymerase chain reaction amplification and typing of rotavirus nucleic acid from stool specimens," Journal of Clinical Microbiology, vol. 28, no. 2, pp. 276-282, 1990.

[17] I. Banerjee, S. Ramani, B. Primrose et al., "Modification of rotavirus multiplex RT-PCR for the detection of G12 strains based on characterization of emerging G12 rotavirus strains from South India," Journal of Medical Virology, vol. 79, no. 9, pp. 1413-1421, 2007.

[18] M. O. Paul and E. A. Erinle, "Influence of humidity on rotavirus prevalence among Nigerian infants and young children with gastroenteritis," Journal of Clinical Microbiology, vol. 15, no. 2, pp. 212-215, 1982.

[19] R. M. Avery, A. P. Shelton, G. M. Beards, O. O. Omotade, O. C. Oyejide, and D. O. Olaleye, "Viral agents associated with infantile gastroenteritis in Nigeria: relative prevalence of adenovirus serotypes 40 and 41, astrovirus, and rotavirus serotypes 1 to 4," Journal of Diarrhoeal Diseases Research, vol. 10, no. 2, pp. 105-108, 1992.

[20] T. I. Ogunsanya, V. O. Rotimi, and A. Adenuga, "A study of the aetiological agents of childhood diarrhoea in Lagos, Nigeria," Journal of Medical Microbiology, vol. 40, no. 1, pp. 10-14, 1994.

[21] G. E. Armah, E. K. Essel, R. H. Asmah, F. R. Anto, and F. N. Binka, "Detection of human group $\mathrm{C}$ rotavirus in Ghanaian children," Ghana Medical Journal, vol. 34, pp. 3-8, 2002.

[22] L. N. Mutanda, S. N. Kinoti, W. Gemert, and E. O. Lichenga, "Age distribution and seasonal pattern of rotavirus infection in children in Kenya," Journal of Diarrhoeal Diseases Research, vol. 2, no. 3, pp. 147-150, 1984.

[23] C. Akoua-Koffi, V. Akran, I. Peenze et al., "Epidemiological and virological aspects Rotavirus diarrhoea in Abidjan, Côte d'Ivoire (1997-2000)," Bulletin de la Societe de Pathologie Exotique, vol. 100, no. 4, pp. 246-249, 2007.

[24] R. T. Espejo, E. Calderon, and N. Gonzalez, "Presence of two distinct types of rotavirus in infants and young children hospitalized with acute gastroenteritis in Mexico City, 1977," Journal of Infectious Diseases, vol. 139, no. 4, pp. 474-477, 1979.

[25] D. H. Dimitrov, D. Y. Graham, and J. Lopez, "RNA electropherotypes of human rotaviruses from North and South America," Bulletin of the World Health Organization, vol. 62, no. 2, pp. 321-329, 1984.

[26] A. D. Steele, M. C. van Niekerk, and M. J. Mphahlele, "Geographic distribution of human rotavirus VP4 genotypes and VP7 serotypes in five South African regions," Journal of Clinical Microbiology, vol. 33, no. 6, pp. 1516-1519, 1995. 
[27] C. K. Ojeh, D. J. Atti, and O. O. Omotade, "Comparison of the genome ds RNA of human rotavirus strains shed in parts of Ibadan, Nigeria," African Journal of Medicine and Medical Sciences, vol. 24, no. 4, pp. 359-363, 1995.

[28] A. Ayub, L. Unicomb, F. Bingnan, and A. Hossain, "Molecular heterogeneity of human group A rotavirus in rural Bangladesh as determined by electrophoresis of genomic ribonucleic acid," Tropical Medicine, vol. 35, no. 2, pp. 53-63, 1993.

[29] R. L. Ward, D. R. Knowlton, and P.-F. L. Hurst, "Reassortant formation and selection following coinfection of cultured cells with subgroup 2 human rotaviruses," Journal of General Virology, vol. 69, no. 1, pp. 149-162, 1988.

[30] B. Biryahwaho, F. Hundley, and U. Desselberger, "Bovine rotavirus with rearranged genome reassorts with human rotavirus. Brief report," Archives of Virology, vol. 96, no. 3-4, pp. 257-264, 1987.

[31] M. I. Adah, A. Wade, and K. Taniguchi, "Molecular epidemiology of rotaviruses in Nigeria: detection of unusual strains with G2P[6] and G8P[1] specificities," Journal of Clinical Microbiology, vol. 39, no. 11, pp. 3969-3975, 2001. 

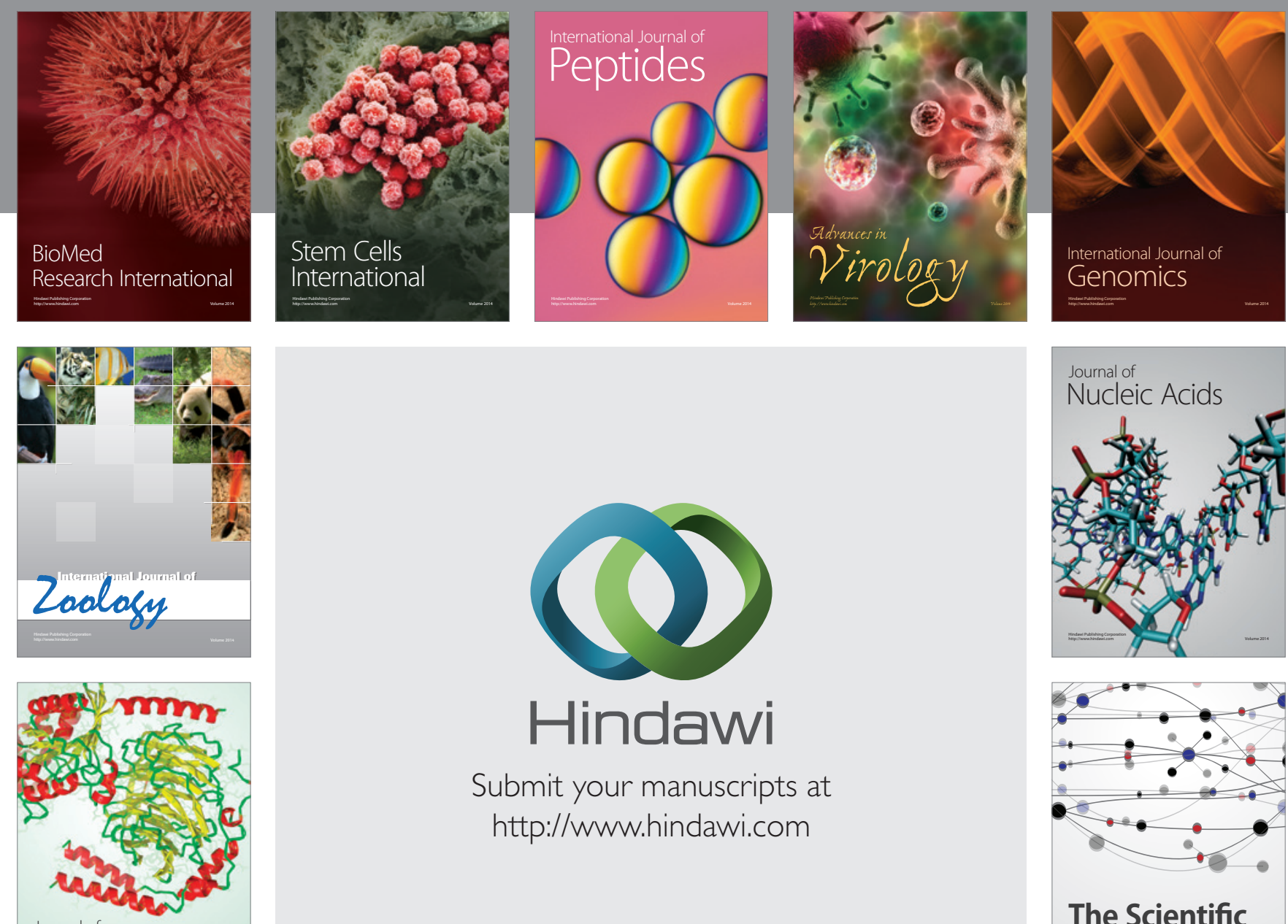

Submit your manuscripts at

http://www.hindawi.com

Journal of
Signal Transduction
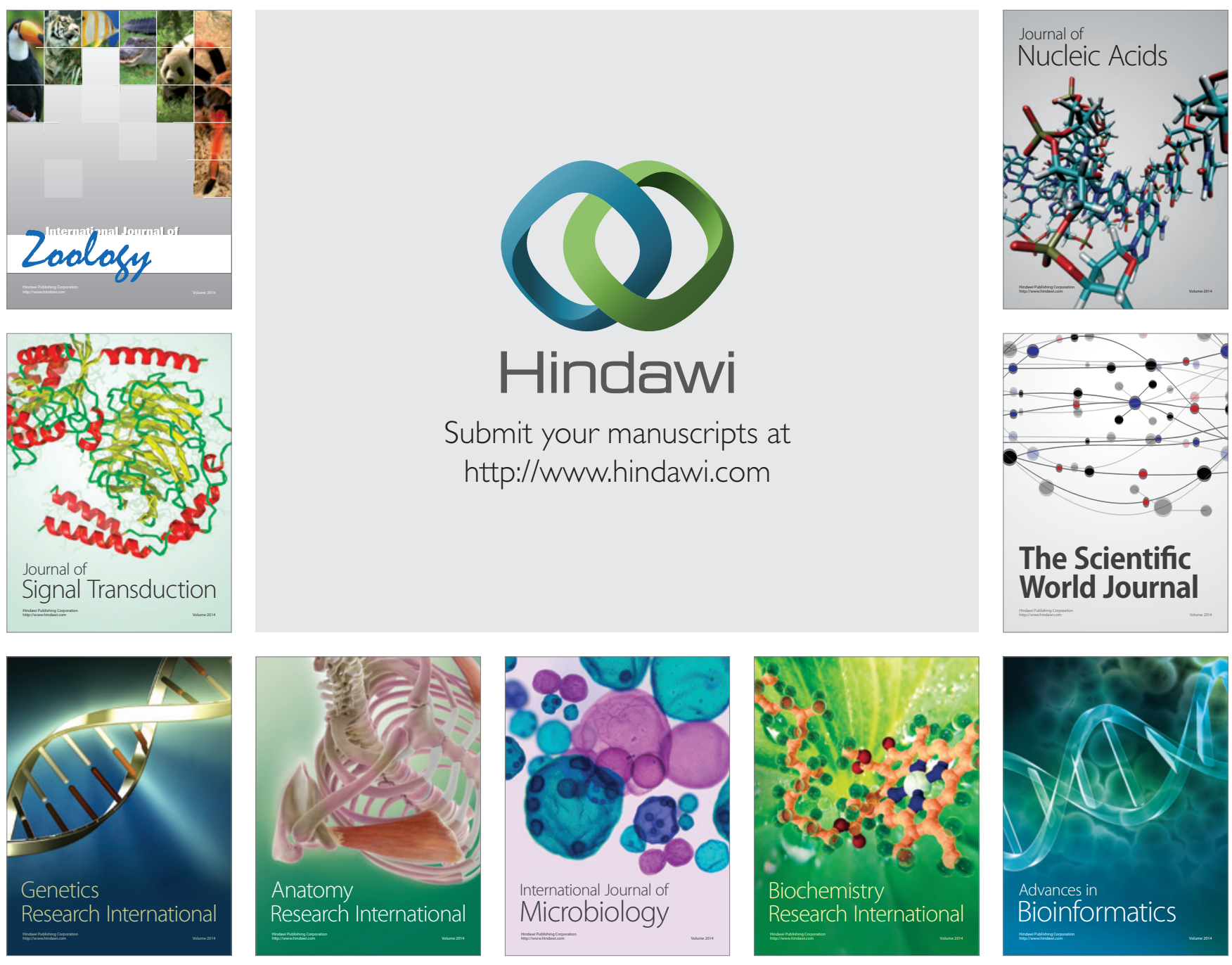

The Scientific World Journal
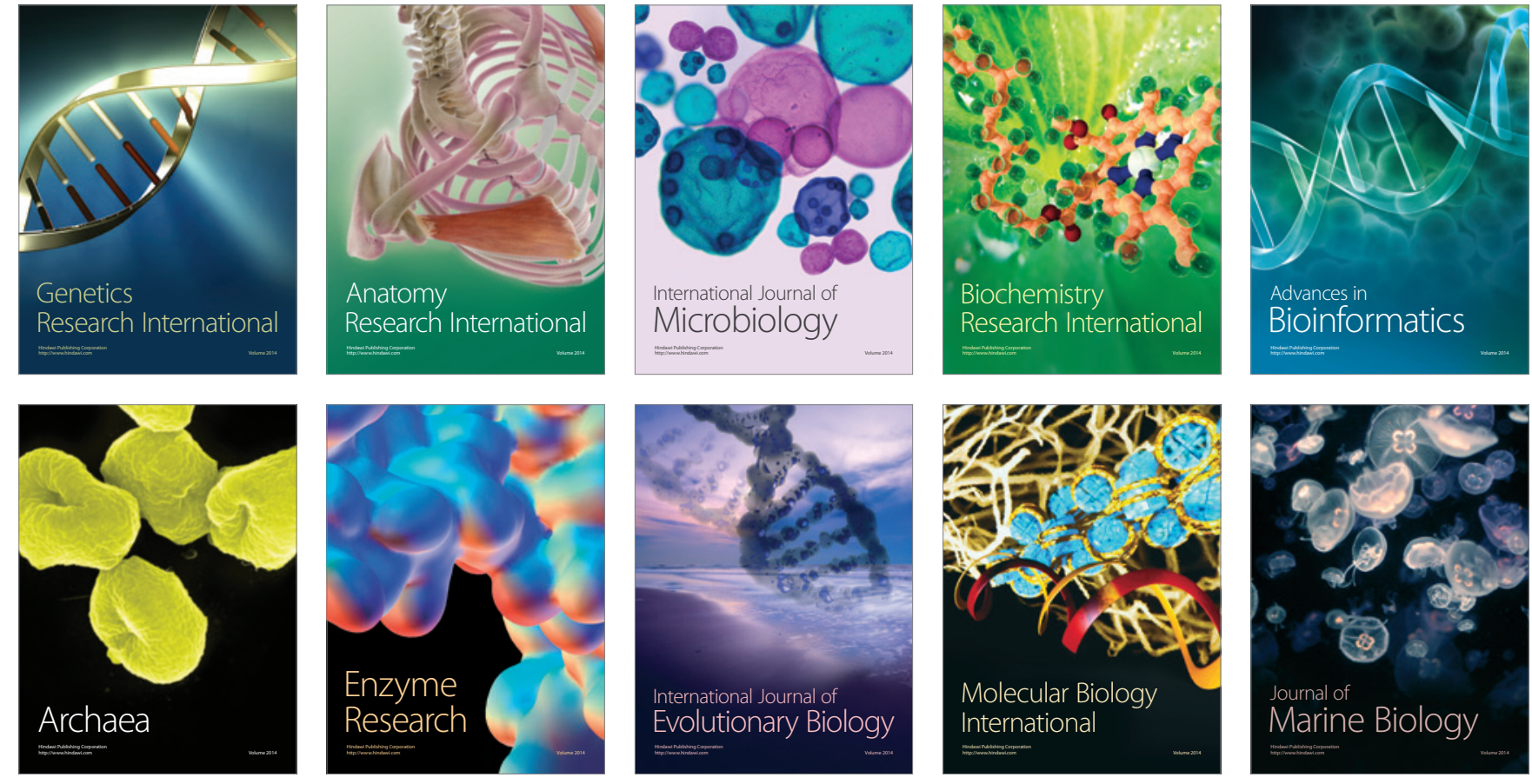